\title{
Preparation of copper-iron bimodal pore catalyst and its performance for higher alcohols synthesis
}

\author{
Mingyue Ding a , Jianguo Liu ${ }^{a}$, Qi Zhang ${ }^{\text {a }}$, Noritatsu Tsubaki ${ }^{\mathrm{b}}$, Tiejun Wang ${ }^{\mathrm{a}, *}$, Longlong Ma ${ }^{\mathrm{a}, *}$ \\ a Key Laboratory of Renewable Energy and Gas Hydrate, Guangzhou Institute of Energy Conversion, Chinese Academy of Sciences, Guangzhou 510640, PR China \\ b Department of Applied Chemistry, School of Engineering, University of Toyama, Gofuku 3190, Toyama 930-8555, Japan
}

\section{A R T I C L E I N F O}

Article history:

Received 18 July 2012

Received in revised form 22 August 2012

Accepted 25 August 2012

Available online 30 August 2012

\section{Keywords:}

Higher alcohols synthesis

Bimodal support

$\mathrm{Cu}-\mathrm{Fe}$ catalyst

Syngas

\begin{abstract}
A B S T R A C T
A multi-functional silica-silica bimodal pore catalyst support was prepared from silica sol and silica gel, which presented two kinds of main pores. Compared to the original silica gel, the obtained bimodal support had the enlarged surface area and decreased pore volume. This kind of bimodal pore support was applied firstly in higher alcohols synthesis, where both the copper and iron elements were supported as active sites. The bimodal pore catalyst exhibited favorite catalytic activity and high selectivity of $\mathrm{C}_{2}^{+} \mathrm{OH}$, due to the well dispersion of active metal sites and high diffusion efficiency of products inside the bimodal pore structures.
\end{abstract}

Crown Copyright @ 2012 Published by Elsevier B.V. All rights reserved.

\section{Introduction}

Higher alcohols synthesis (HAS) from hydrogenation of carbon monoxide has drawn much attention due to its potential application as a promising route for the production of clean fuels and petrochemical feed stocks from coal, natural gas and biomass [1,2]. In recent years several catalytic systems for HAS, including $\mathrm{MoS}_{2}$-based catalysts, modified methanol synthesis catalysts and modified Fischer-Tropsch (F-T) catalysts have been developed [3-5]. Among those catalytic systems, the Cu-based catalyst containing metal active F-T element ( $\mathrm{Fe}, \mathrm{Co}$ or $\mathrm{Ni}$ ) is considered as one of the most promising catalysts due to the strong ability to promote carbon chain growth for the F-T element [6,7].

Especially, the use of iron-copper catalyst is attractive for higher alcohols synthesis with low $\mathrm{H}_{2} / \mathrm{CO}$ ratio syngas derived from coal or biomass due to its higher water-gas shift activity and lower cost $[8,9]$. Sibilia et al. [10] found that the addition of iron into copper-based methanol synthesis catalysts promoted the carbon chain growth for higher alcohols synthesis. Xu et al. [11] suggested that the introduction of Fe into the $\mathrm{CuMnZrO}_{2}$ catalyst strengthened the interaction between copper and iron, facilitating the formation of higher alcohols and hydrocarbons. Unfortunately, there is still the formation of many byproducts such as carbon dioxide and hydrocarbons during HAS [12]. Thus, how to improve the activity and selectivity of $\mathrm{Cu}-\mathrm{Fe}$ based catalysts for HAS becomes the key of research.

The bimodal support where both large pore and small pore coexist has excellent advantages for improving the catalytic activity and selectivity of the target product because the large pores provide rapid

\footnotetext{
* Corresponding authors. Tel.: +8620 87057751; fax: + 862087057737.

E-mail addresses: wangtj@ms.giec.ac.cn (T. Wang), mall@ms.giec.ac.cn (L. Ma).
}

transportations of reactant and product molecules, while the small pores simultaneously provide a large supported metal area [13,14]. Inui et al. [15] developed a kind of bimodal $\mathrm{Ni} / \mathrm{SiO}_{2}$ catalyst, which presented the high activity for methanation of $\mathrm{CO}_{2}$. Tsubaki et al. $[16,17]$ prepared some bimodal supports such as $\mathrm{SiO}_{2}-\mathrm{SiO}_{2}, \mathrm{Al}_{2} \mathrm{O}_{3}-\mathrm{SiO}_{2}$ and $\mathrm{ZrO}_{2}-\mathrm{SiO}_{2}$ and so on, which presented excellent performances in promoting the activity and selectivity for Fischer-Tropsch synthesis. The spatial and chemical characteristics of bimodal support provide us a new way to solve the obstacle in HAS. However, an application of this kind of bimodal support to higher alcohols synthesis is rarely reported. Thus, in the present work the preparation of $\mathrm{Cu}-\mathrm{Fe}$ supported bimodal catalyst and its application for higher alcohols synthesis were investigated.

\section{Experimental}

\subsection{Catalyst preparation}

The bimodal support was prepared by incipient-wetness impregnation of commercially available silica gel with silica sol. Under the conditions of ultrasonic and $80{ }^{\circ} \mathrm{C}$, the silica sol was impregnated into original silica gel by incipient-witness method. After the impregnation the support was dried in air at $120{ }^{\circ} \mathrm{C}$ for $12 \mathrm{~h}$, and then calcined in air at $600{ }^{\circ} \mathrm{C}$ for $2 \mathrm{~h}$. The silica sol loading of the obtained bimodal pore support was $20 \mathrm{wt} \%$.

The $\mathrm{Cu}-\mathrm{Fe}$ supported catalyst was prepared by incipient-wetness impregnation of different supports such as SG10, SG0110 and bimodal support, with a solution containing $\mathrm{Fe}\left(\mathrm{NO}_{3}\right)_{3}, \mathrm{Cu}\left(\mathrm{NO}_{3}\right)_{2}$ and $\mathrm{KNO}_{3}$ in the required mass ratio (Fe:Cu:K: support $=0.3: 0.2: 0.05: 1$ ). The 
catalyst precursors were dried in air at $120^{\circ} \mathrm{C}$ for $12 \mathrm{~h}$, and then calcined in air at $450{ }^{\circ} \mathrm{C}$ for $3 \mathrm{~h}$.

\subsection{Catalyst characterizations}

BET surface area, pore volume and average pore diameter of the catalysts were measured by $\mathrm{N}_{2}$ physisorption at $-196{ }^{\circ} \mathrm{C}$ using a Micromeritics ASAP 2010 instruments. Temperature program reduction of hydrogen $\left(\mathrm{H}_{2}\right.$-TPR) was carried out in a U-tube quartz reactor with a hydrogen-argon mixture (containing 5 vol\% of hydrogen) as the reductive gas.

Powder X-ray diffraction patterns (XRD) of the catalyst samples were measured on a D/max-RA X-ray diffractometer (Rigaku, Japan) with $\mathrm{Cu} \mathrm{K \alpha}$ radiation $(\lambda=0.154 \mathrm{~nm})$ operated at $40 \mathrm{kV}$ and $100 \mathrm{~mA}$.

\subsection{Catalyst pretreatment and testing}

The HAS was conducted in a fixed-bed, stainless flow microreactor. All catalysts were reduced in hydrogen atmosphere at $300{ }^{\circ} \mathrm{C}$ and atmospheric pressure. After on-line activation described above and cooling to $180{ }^{\circ} \mathrm{C}$, syngas was introduced into reactor, followed by a rise of reaction temperature with a rate of $2{ }^{\circ} \mathrm{C} / \mathrm{min}$. All synthesis reaction was employed at $5.0 \mathrm{MPa}, 320{ }^{\circ} \mathrm{C}$ and $6000 \mathrm{~h}^{-1}$ with the $\mathrm{H}_{2} / \mathrm{CO}$ of 2.0 . Both gaseous and liquid products were analyzed off-line by gas chromatographs. $\mathrm{H}_{2}, \mathrm{CO}, \mathrm{CH}_{4}$ and $\mathrm{CO}_{2}$ were determined by thermal conductivity detector (TCD) with a TDX-101 column. The alcohols and hydrocarbons were analyzed by flame ionization detector (FID) with a Porapack-Q column.

\section{Results and discussion}

\subsection{Textural properties of bimodal support}

The pore size distribution of silica gel SG10, silica sol SG0110 and bimodal pore supports is shown in Fig. 1. It is clear that the pore size of silica sol SG0110 and silica gel SG10 is 3 and $61 \mathrm{~nm}$, respectively. After impregnation of the silica sol into silica gel, the obtained silica bimodal support contains 16 and $60 \mathrm{~nm}$ pores meantime, unlike uniformly distributed silica gel SG10 and silica sol SG0110. In the calcination step, the $16 \mathrm{~nm}$ pores are formed probably by the silica sol through dehydration of the surface $\mathrm{OH}$ groups of silica sol particles in the large pores of the silica gel [18]. The large pore size of the bimodal support decreases slightly. In addition, the BET surface area of the bimodal support increases from $95 \mathrm{~m}^{2} \mathrm{~g}^{-1}$ (from silica gel SG10) to $107 \mathrm{~m}^{2} \mathrm{~g}^{-1}$ due to the contribution from the newly formed small pores, as summarized in Table 1. As the silica porous structure is formed inside the large pores of silica gel SG10, the pore volume of obtained bimodal support decreases from $1.32 \mathrm{ml} \mathrm{g}^{-1}$ of SG10 to $0.64 \mathrm{ml} \mathrm{g}^{-1}$. The increased BET surface area and decreased pore volume suggest that the particles of silica sol enter the large pores and deposit on the inner walls of SG10 to form the small pore structures.

In addition, from Table 1 it can be seen that in the $\mathrm{Cu}-\mathrm{Fe}$ supported bimodal catalyst exist two pore structures, indicating that both the copper and iron elements do not block the entrance of pore structures. The decrease of pore sizes for the bimodal derived catalyst suggests that the metal elements have entered into the large pores of the bimodal support. For the SG0110 derived catalyst, the BET surface area decreases markedly from $737 \mathrm{~m}^{2} \mathrm{~g}^{-1}$ of silica sol to $110 \mathrm{~m}^{2} \mathrm{~g}^{-1}$, which may be attributed to the covering of large amounts of metal oxide particles on the surface of silica sol, resulting in the decrease of surface area.

\subsection{Reduction behavior of bimodal catalyst}

The $\mathrm{H}_{2}$-TPR profiles of the $\mathrm{Cu}-\mathrm{Fe}$ based catalysts prepared from the bimodal support, SG10 and SG0110 are shown in Fig. 2. One main
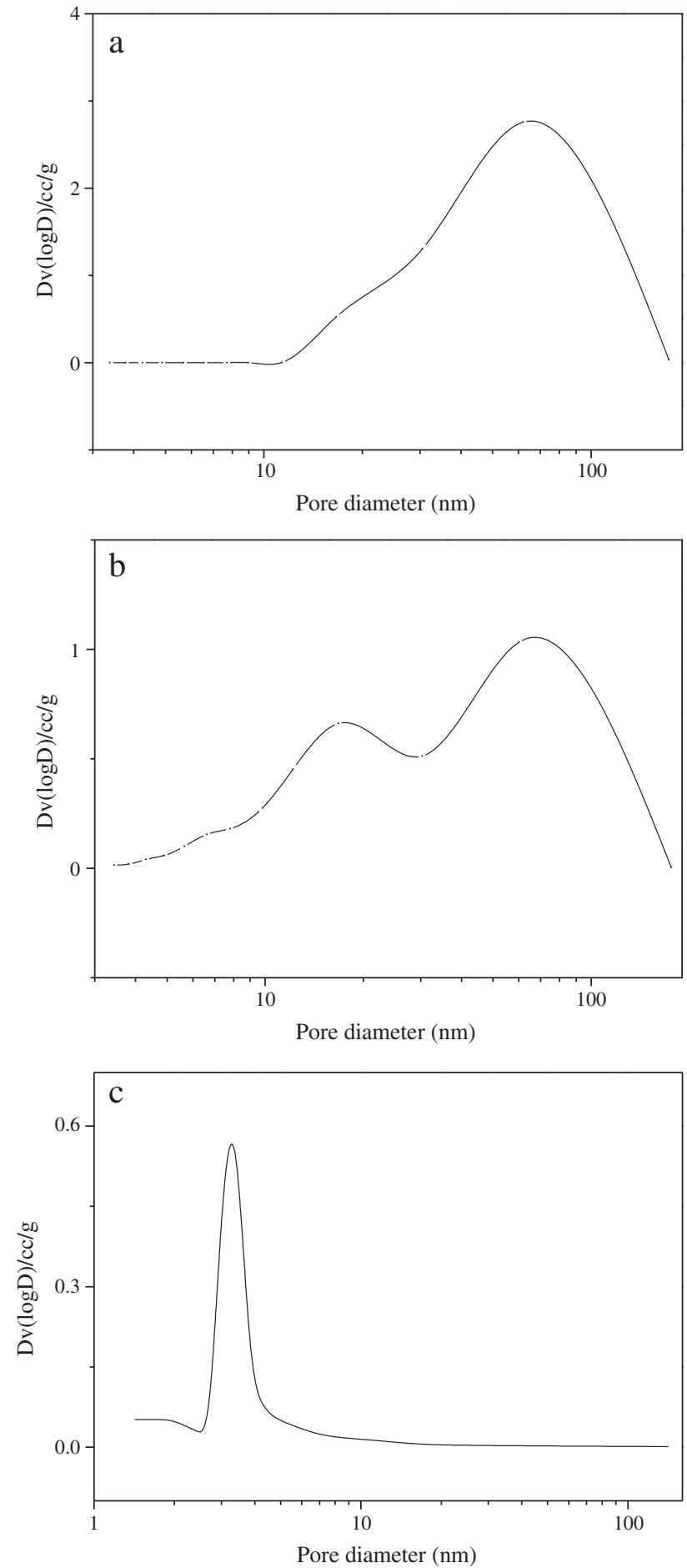

Fig 1. The pore size distributions of (a) the SG10 support, (b) the $\mathrm{SiO}_{2}-\mathrm{SiO}_{2}$ bimodal support, and (c) the SG0110 support.

peak with one shoulder peak appeared at $200-380{ }^{\circ} \mathrm{C}$ for all of the catalysts, corresponding to the reduction of $\mathrm{CuO} \rightarrow \mathrm{Cu}$ and $\mathrm{Fe}_{2} \mathrm{O}_{3} \rightarrow \mathrm{Fe}_{3} \mathrm{O}_{4}$, respectively [5]. In addition, a tail peak appeared at $400-550{ }^{\circ} \mathrm{C}$ in the $\mathrm{H}_{2}$-TPR profiles, which could be attributed to the reduction of $\mathrm{Fe}_{3} \mathrm{O}_{4}$ [19]. The amount of $\mathrm{H}_{2}$ consumed during different reduction stages, obtained from integrating the area of the corresponding reduction peak, is summarized in Table 2. For the $\mathrm{Cu}-\mathrm{Fe}$ catalysts prepared from the bimodal support, SG10 and SG0110, the amounts of $\mathrm{H}_{2}$ consumption for reduction peaks at lower temperature range $\left(200-380{ }^{\circ} \mathrm{C}\right)$ (0.65 $\mathrm{mol} \mathrm{H}_{2} / \mathrm{mol} \mathrm{M}$ for the SG10 derived catalyst, $0.71 \mathrm{~mol} \mathrm{H}_{2} / \mathrm{mol} \mathrm{M}$ 
Table 1

The textural properties of various $\mathrm{Cu}-\mathrm{Fe}$ catalysts and corresponding supports.

\begin{tabular}{|c|c|c|c|c|c|c|c|c|}
\hline \multirow[t]{2}{*}{ Catalyst } & \multicolumn{2}{|c|}{ Surface area $/ \mathrm{m}^{2} \mathrm{~g}^{-1}$} & \multicolumn{2}{|c|}{ Pore vol./. $\mathrm{mlg}^{-1}$} & \multicolumn{2}{|c|}{ Pore size/nm } & \multicolumn{2}{|c|}{$\mathrm{d}_{\mathrm{XRD}} / \mathrm{nm}$} \\
\hline & Support & Catalyst & Support & Catalyst & Support & Catalyst & $\mathrm{d}_{\mathrm{Cu}}$ & $\mathrm{d}_{\mathrm{Fe}}$ \\
\hline SG10 & 95 & 38 & 1.32 & 0.36 & 61 & 14.8 & 29.8 & 18.5 \\
\hline Bimodal & 107 & 80 & 0.64 & 0.30 & 16,60 & $8.2,25.4$ & 21.1 & 15.1 \\
\hline SG0110 & 737 & 110 & 0.32 & 0.12 & 3 & 1.7 & 7.5 & 6.7 \\
\hline
\end{tabular}

Silica sol loading of bimodal support: $20 \mathrm{wt} \%$.

for the bimodal derived catalyst and $0.70 \mathrm{~mol} \mathrm{H}_{2} / \mathrm{mol} \mathrm{M}$ for the SG0110 derived catalyst) are close to the theoretical value for the reduction of metal oxides to $\mathrm{Cu}$ and $\mathrm{Fe}_{3} \mathrm{O}_{4}\left(0.72 \mathrm{~mol} \mathrm{H}_{2} / \mathrm{mol} \mathrm{M}\right)$. The small amount of $\mathrm{H} 2$ consumed for reduction peak at higher temperature $\left(400-550{ }^{\circ} \mathrm{C}\right)$ corresponds to the reduction of $\mathrm{Fe}_{3} \mathrm{O}_{4}$. Additionally, from Fig. 2 it can be found that the reduction temperature of metal oxides in the SG0110 derived catalyst is the lowest compared to the bimodal and SG10 derived catalysts. Due to the covering of large amounts of copper and iron elements on the surface of silica sol SG0110, while the entering of metal oxide particles inside the large pores of SG10 and bimodal support as shown in Table 1, the reduction of $\mathrm{CuO}$ and $\mathrm{Fe}_{2} \mathrm{O}_{3}$ outside the pore structures is easier than that inside the large pores, resulting in the decrease of reduction temperature for the SG0110 derived catalyst. On the other hand, the reduction temperature of the $\mathrm{Cu}-\mathrm{Fe}$ supported bimodal catalyst shifts slightly towards higher temperature compared to the SG10 derived catalyst. It is possible that both the $\mathrm{Cu}$ and Fe elements are better dispersed inside the bimodal support compared to that inside the original silica gel due to larger surface area of the bimodal derived catalyst, enhancing the interaction of metal-support and restraining the reduction of metal oxides in the Cu-Fe bimodal catalyst.

\subsection{Phase compositions of the catalysts}

The XRD patterns of the fresh and used catalysts are showed in Fig. 3. From Fig. 3a it can be found that the XRD patterns of all the fresh catalysts show the mainly diffraction peaks at $2 \theta$ values of $35.5,38.8,48.5,58.2,61.5,66.2,68.1,72.4,74.9^{\circ}$ and $33.3,35.6^{\circ}$, corresponding to $\mathrm{CuO}$ (JCPDS card No.48-1548) and $\mathrm{Fe}_{2} \mathrm{O}_{3}$ (JCPDS card No.33-0664), respectively. Compared to the bimodal and SG10 derived catalysts, the intensity of diffraction peaks in the SG0110 derived catalyst is the lowest, which may be attributed to the well dispersion of $\mathrm{CuO}$ and $\mathrm{Fe}_{2} \mathrm{O}_{3}$ on the surface of silica sol, decreasing the crystallite size of metal oxides [20]. In addition, the peak intensity of $\mathrm{Cu}-\mathrm{Fe}$ supported bimodal catalyst is lower slightly than that of the

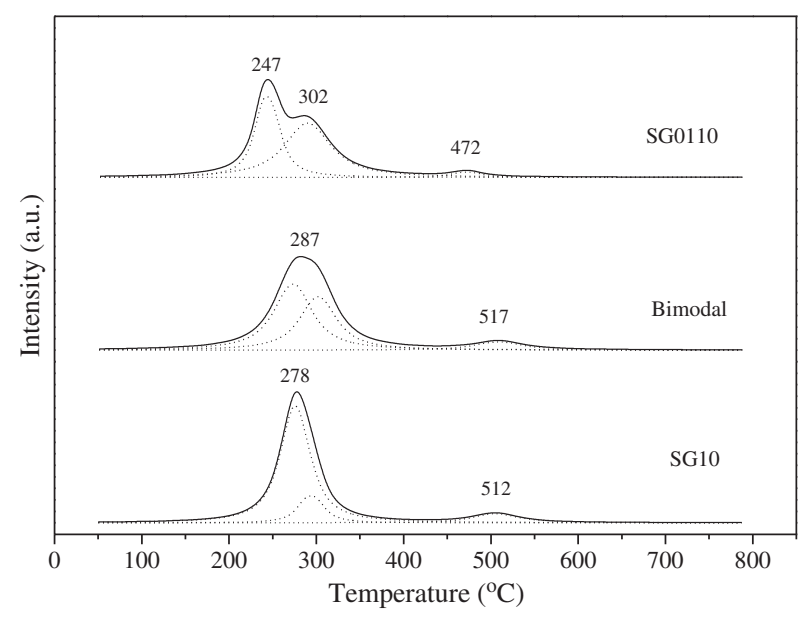

Fig. 2. The $\mathrm{H}_{2}$-TPR profiles of the catalysts.
Table 2

The reaction performances of various $\mathrm{Cu}-\mathrm{Fe}$ based catalysts.

\begin{tabular}{lllllll}
\hline Catalysts & \multirow{2}{*}{ XCO (\%) } & \multicolumn{3}{l}{ Selectivity (\%) } & \multirow{2}{*}{$\begin{array}{l}\mathrm{ROH} \mathrm{STY} \\
\left(\mathrm{g} \mathrm{ml}^{-1} \cdot \mathrm{h}^{-1}\right)\end{array}$} & $\begin{array}{l}\mathrm{C}_{2}^{+} \mathrm{OH} / \\
\mathrm{CH}_{3} \mathrm{OH}\end{array}$ \\
\cline { 2 - 5 } & & $\mathrm{ROH}$ & $\mathrm{CO}_{2}$ & $\mathrm{HC}$ & & \\
\hline SG10 & 31 & 49.17 & 35.46 & 15.37 & 0.15 & 1.26 \\
Bimodal & 38 & 51.17 & 35.71 & 13.13 & 0.28 & 1.46 \\
SG0110 & 54 & 42.23 & 42.89 & 14.89 & 0.36 & 0.73 \\
\hline
\end{tabular}

Reaction conditions: $\mathrm{T}=320^{\circ} \mathrm{C}, \mathrm{P}=5.0 \mathrm{MPa}, \mathrm{GHSV}=6000 \mathrm{~h}^{-1}, \mathrm{n}\left(\mathrm{H}_{2}\right) / \mathrm{n}(\mathrm{CO})=2.0$. STY: space time yield.

$\mathrm{Cu}-\mathrm{Fe}-\mathrm{SG} 10$ catalyst. Combined to the results of BET and $\mathrm{H}_{2}$-TPR, it is considered that both the copper and iron elements are better dispersed inside the bimodal support compared to that inside the original silica gel.

From Fig. 3b it can be found that the diffraction peaks of metal oxides disappeared and new diffraction peaks corresponding to metallic copper were observed in all of the used catalysts. The peak intensity of metallic $\mathrm{Cu}$ in the SG0110 derived catalyst is the lowest, which may be attributed to the well dispersion of metal elements on the surface of SG0110 support. In addition, the peak intensity of metallic copper of the bimodal derived catalyst is slightly higher than that of the SG10 derived catalyst, indicating that the amounts of active metals of bimodal catalyst are probable more than that of the SG10 catalyst.

It is also found from Fig. 3b that no diffraction peaks of reduced iron species and/or iron carbides are observed in the used catalysts.
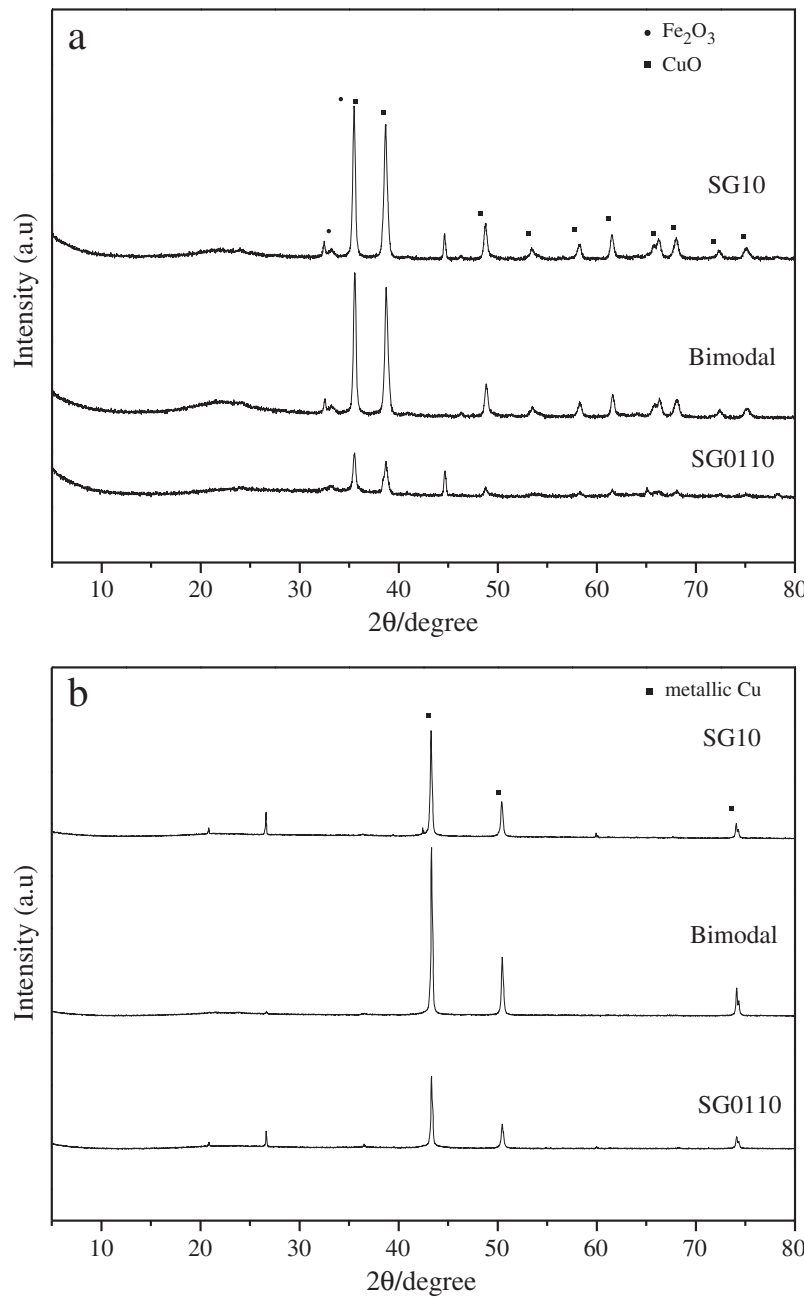

Fig. 3. The XRD patterns of $\mathrm{Cu}-\mathrm{Fe}$ based catalyst prepared from different supports (a) the fresh catalysts, and (b) the used catalysts. 
It is known that the intensity of $\mathrm{Fe}_{2} \mathrm{O}_{3}$ diffraction peaks in the fresh catalysts is weak, indicating that the iron species are well dispersed by the support. From the $\mathrm{H}_{2}$-TPR results it can be found that the magnetite reduced is difficult to further reduce and carbonize under the present reaction conditions, which may be attributed to the enhancement of interaction of iron-support. Therefore, it is possible that the well dispersion of iron species and the difficulty for further reduction and carburization of iron oxides during reaction, restraining the detection of reduced iron species and/or iron carbides in the used catalysts by XRD.

\subsection{HAS performances}

Higher alcohols synthesis performances of the $\mathrm{Cu}-\mathrm{Fe}$ catalysts prepared from the bimodal support, SG10 and SG0110 are listed in Table 3. The catalyst prepared from SG0110 support has the largest surface area but the smallest pore diameter. It exhibits the highest catalytic activity and the lowest alcohols selectivity. From the detailed product distribution of alcohols as shown in Fig. 4 it can be found that the $\mathrm{Cu}-\mathrm{Fe}-\mathrm{SG} 0110$ catalyst presents the highest methanol selectivity. For the catalyst prepared from SG10 support which has the lowest surface area, CO conversion is the lowest. The catalytic activity of the catalyst prepared from bimodal support is higher than that of the SG10 catalyst, and the alcohols selectivity is the highest. From the results of product distribution (Fig. 4) it can be seen that the methanol selectivity is the lowest for the bimodal derived catalyst. In addition, the $\mathrm{C}_{2}^{+} \mathrm{OH}$ selectivity of the SG10 derived catalyst is as high as that of the bimodal derived catalyst.

The activities and selectivities of the HAS catalysts are markedly depending on their pore structure. Fujimoto et al. [21,22] reported that the propagation of carbon-carbon chain occurred more easily on the catalyst with a lower surface area and larger metallic particle size. According to the results of BET and XRD in the present study, the SG0110 derived catalyst has the largest surface area and the highest metal dispersion. Simultaneously, it presents the highest catalytic activity, suggesting that the SG0110 derived catalyst provides the most active sites for hydrogenation of carbon monoxide. Additionally, its small pore size and slow diffusion efficiency restrict carbon chain growth of methanol, resulting in the highest methanol selectivity. When the pore size is larger, the carbon growth of methanol is easier and propagation of the primary product is more effective. Also lower BET surface area of large-pore support determines a larger metallic size and smaller active metal dispersion. Based on these reasons, the $\mathrm{C}_{2}^{+} \mathrm{OH}$ selectivity of the catalyst prepared from bimodal support is the highest. Due to the larger pore existing in the catalyst prepared from SG10 support, the selectivity of higher alcohols is also high. On the other hand, HAS rates on $\mathrm{Cu}-\mathrm{Fe}$ catalyst can be improved by increasing the dispersion of active metals. Compared

Table 3

Quantitative results of $\mathrm{H}_{2}$ consumption for the $\mathrm{Cu}-\mathrm{Fe}$ based catalysts prepared from the bimodal support, SG10 and SG0110 in $\mathrm{H}_{2}-\mathrm{TPR}^{\mathrm{a}}$.

\begin{tabular}{lll}
\hline Catalysts & Peak $\left({ }^{\circ} \mathrm{C}\right)$ & $\frac{\mathrm{H}_{2} \text { consumption }}{\mathrm{mol} \mathrm{H}_{2} / \mathrm{mol} \mathrm{M}^{\mathrm{b}}}$ \\
\hline SG10 & 276 & 0.54 \\
& 294 & 0.11 \\
Bimodal & 505 & 0.07 \\
& 273 & 0.40 \\
SG0110 & 303 & 0.31 \\
& 510 & 0.06 \\
& 243 & 0.30 \\
& 291 & 0.40 \\
\hline
\end{tabular}

a The $\mathrm{H}_{2}$ consumption was measured from the area under the corresponding peak.

b $\mathrm{M}=\mathrm{Fe}+\mathrm{Cu}$.

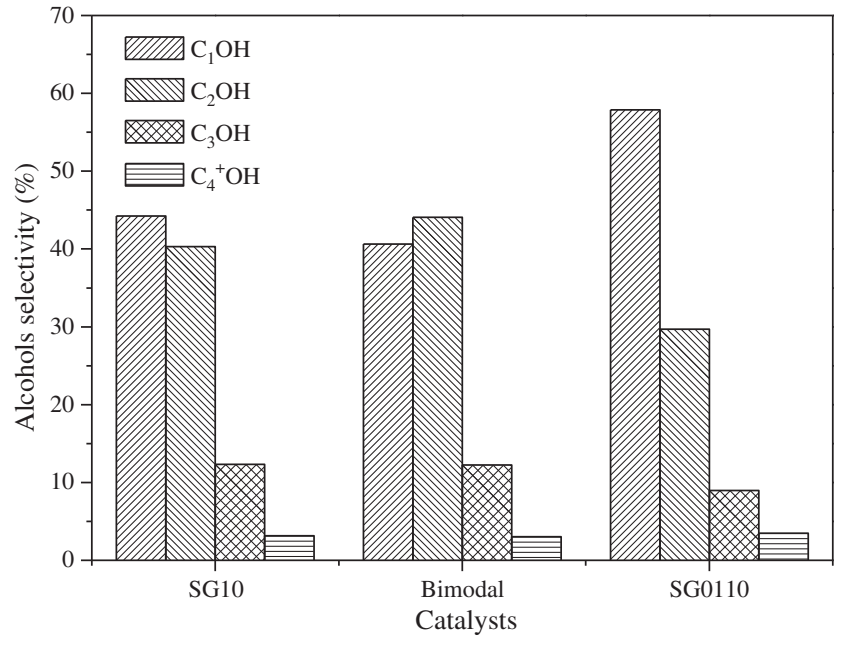

Fig. 4. The selectivity of alcohols for various $\mathrm{Cu}-\mathrm{Fe}$ based catalysts.

to the SG10 derived catalyst, the bimodal derived catalyst has higher metal dispersion due to its larger BET surface area, and accelerated diffusion rate derived from the bimodal structures presents a higher CO conversion.

\section{Conclusions}

The multi-functional silica-silica bimodal pore support was firstly applied in higher alcohols synthesis reaction. The $\mathrm{Cu}-\mathrm{Fe}$ based catalyst prepared by this kind of support exhibited excellent HAS performances due to the spatial and chemical effects of silica-silica bimodal support. Because of larger and smaller pores coexisting in the bimodal derived catalyst, where larger pores of bimodal catalyst provided pathways for carbon chain growth of methanol and high diffusion efficiency of products, the methanol selectivity was the lowest. On the other hand, compared to the catalyst prepared from the original SG10 support, the bimodal catalyst presented higher surface area and provided higher active metal dispersion, promoting the catalytic activity for HAS.

\section{Acknowledgments}

The authors gratefully acknowledge the financial support from the Natural Science Foundation of China (51206172, 51161140331, 51076158) and the Special Funds for Major State Basic Research projects (2011BAD22B06).

\section{References}

[1] R. Herman, Studies in Surface and Catalyst, Elsevier, Amsterdam, 1990. (Chapter 7).

[2] P. Johnston, G.J. Hutchings, N.J. Coville, K.P. Finch, J.R. Moss, Applied Catalysis A 186 (1999) 245

[3] K.J. Smith, R.B. Anderson, Journal of Catalysis 85 (1984) 428.

[4] J.M. Camposmartin, A. Guerreroruiz, J.L.G. Fierro, Journal of Catalysis 156 (1995) 208.

[5] I. Boz, M. Sahibzada, I.S. Metcalfe, Industrial and Engineering Chemistry Research 33 (1994) 2021.

[6] J.A. Dalmon, P. Chaumette, C. Mirodatos, Catalysis Today 15 (1992) 101.

[7] G.R. Sheffer, R.A. Jacobson, T.S. King, Journal of Catalysis 116 (1989) 95

[8] M. Lin, K. Fang, D. Li, Y. Sun, Catalysis Communications 9 (2008) 1869.

[9] R. Xu, C. Yang, W. Wei, W. Li, Y. Sun, T. Hu, Journal of Molecular Catalysis A 221 (2004) 51.

[10] J.A. Sibilia, J.M. Dominguez, R.G. Herman, K. Klier, Preprints. American Chemical Society. Division of Fuel Chemistry 29 (1984) 261.

[11] R. Xu, Z.Y. Ma, C. Yang, W. Wei, Y.H. Sun, Catalysis Letters 81 (2004) 91.

[12] Y. Lu, F. Yu, J. Hu, J. Liu, Applied Catalysis A 429 (2012) 48.

[13] O. Levenspiel, Chemical Reaction Engineering, 2nd ed. Wiley, New York, 1972. p. 496.

[14] Y. Zhang, Y. Yoneyama, N. Tsubaki, Chemical Communications (2002) 1216. 
[15] T. Inui, M. Funabiki, M. Suehiro, T. Sezume, Journal of the Chemical Society, Faraday 175 (1979) 787.

[16] Y. Zhang, R.Q. Yang, M. Koike, H. Sukamon, V. Tharapong, N. Tsubaki, Applied Catalysis A 292 (2005) 252

[17] Y. Zhang, M. Koike, N. Tsubaki, Catalysis Letters 91 (2005) 193.

[18] Y. Zhang, M. Shinoda, N. Tsubaki, Catalysis Today 93-95 (2004) 55.
[19] Y. Yang, Z.C. Tao, C.H. Zhang, H. Wang, L. Tian, Y.Y. Xu, H.W. Xiang, Y.W. Li, Journal of Fuel Chemistry and Technology 32 (2004) 717.

[20] K.W. Jun, H.S. Roh, K.S. Kim, J.S. Ryu, K.W. Lee, Applied Catalysis A 259 (2004) 221

[21] L. Fan, K. Yokota, K. Fujimoto, AICHE Journal 38 (1992) 1639

[22] S. Sun, N. Tsubaki, K. Fujimoto, Journal of Chemical Engineering Japan 33 (2000) 232. 